\title{
Carbonaceous Materials Original to Impact Plume Condensates in a 3.24 Ga Impact-Derived Spherule Deposit, Barberton Greenstone Belt, South Africa
}

\author{
E.E. Scroggs*, J.J. Friel*, A.E. Davatzes* \\ * Department of Earth and Environmental Science, Temple University, 1901 North $13^{\text {th }}$ Street, \\ Beury Hall, Philadelphia, PA 19130
}

Carbonaceous materials have been associated with spherules formed by impact processes in a 3.24 billion year old greenstone belt in South Africa [1,2]. Various explanations for the carbonaceous materials have been proposed and include: (1) original components from the impact plume condensate and (2) microbial activity $[2,3]$. The spherules range from 0.25 to 2 $\mathrm{mm}$ in diameter and consist of phyllosilicate minerals (sericite, chlorite), quartz $\left(\mathrm{SiO}_{2}\right)$, oxides and sulfides, barite, and (Ni, Cr)-rich spinels [4].

Petrographic and electron microanalytical studies reveal the presence of carbonaceous material in the sections containing high concentrations of spherules, but not in those with low concentrations of spherules. Carbon was detected within impact spherules, along spherule boundaries (Fig. 1) and within microfractures. Carbonaceous matter was detected in areas rich in quartz $\left(\mathrm{SiO}_{2}\right)$, but not in areas rich in sericite $\left(\mathrm{KAl}_{2}\left(\mathrm{Si}_{3} \mathrm{Al}\right) \mathrm{O}_{10}(\mathrm{OH}, \mathrm{F})_{2}\right)$. The boundaries between the two dominant phases, quartz and phyllosilicates, are very abrupt, and each phase displays a distinct crystal habit (Fig. 2). Carbonaceous matter was identified along microfractures separating the two phases (Fig. 3). The spherule bed shows evidence of microbial activity, including biologically induced microtubular structures and a feature having a physical morphology similar to cyanobacteria (Figs. 4, 5). While carbon can originate from the cellular materials of microbes, there is not sufficient microstructural evidence to make this claim without further research.

EPMA images suggest that the carbon was mobilized from within the spherules during diagenesis. While there is some evidence for microbial activity, the location of carbon along microfractures and within the impact spherules suggests the carbonaceous materials were original to the impact plume condensates, which were then subsequently mobilized by diagenetic processes. If the carbonaceous components were not original to the impact plume condensates, the carbon would be more widely dispersed throughout the impact beds, and not just localized to the spherule interiors and microfractures.

\section{References:}

[1] Kröner, A., et al., 1991, Earth and Planetary Science Letters, v. 103, p. 41-54.

[2] Walsh, M., 1992, Precambrian Research, v. 54, p. 271-293.

[3] Tice, M. and Lowe D., 2004, Nature, v. 431, p. 549-552.

[4] Krull-Davatzes, A., et al., 2010, Earth and Planetary Science Letters, v. 296, p. 319-328. 


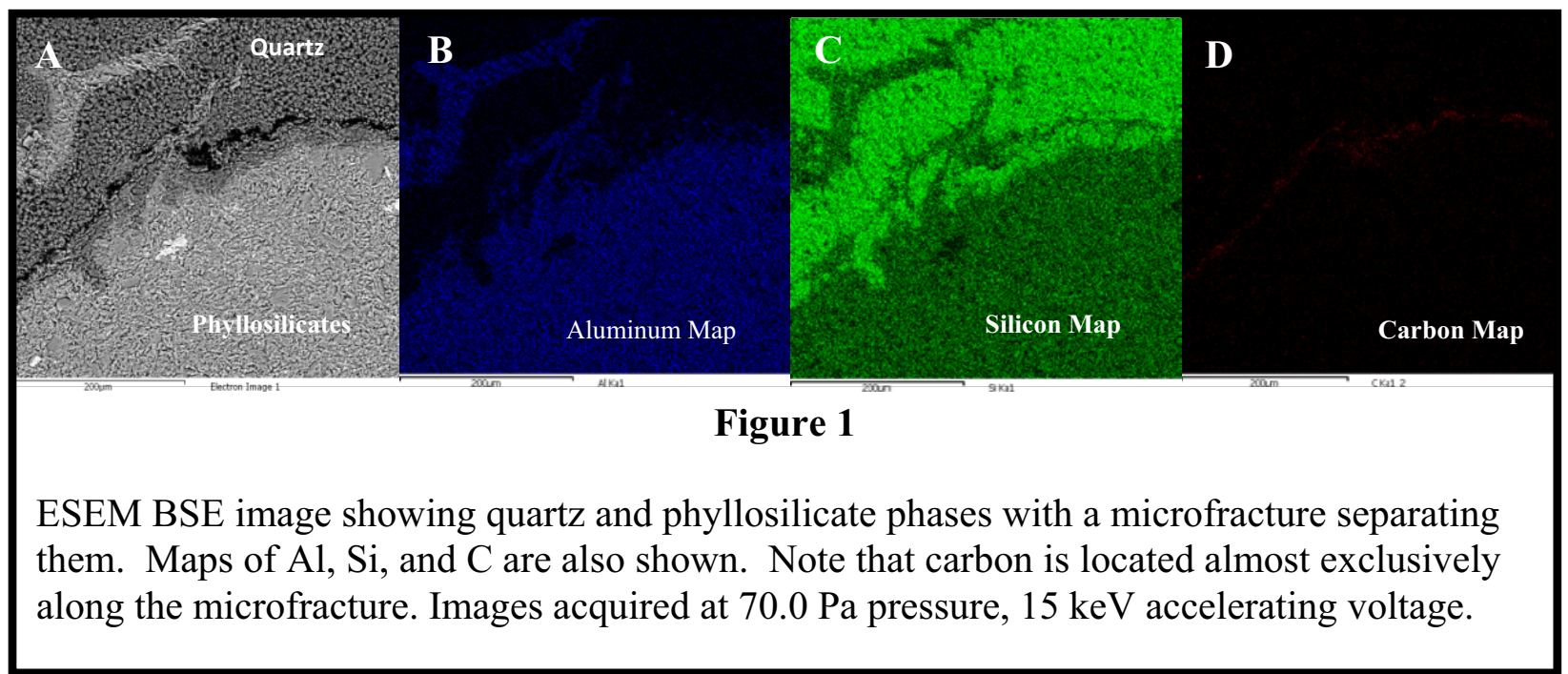

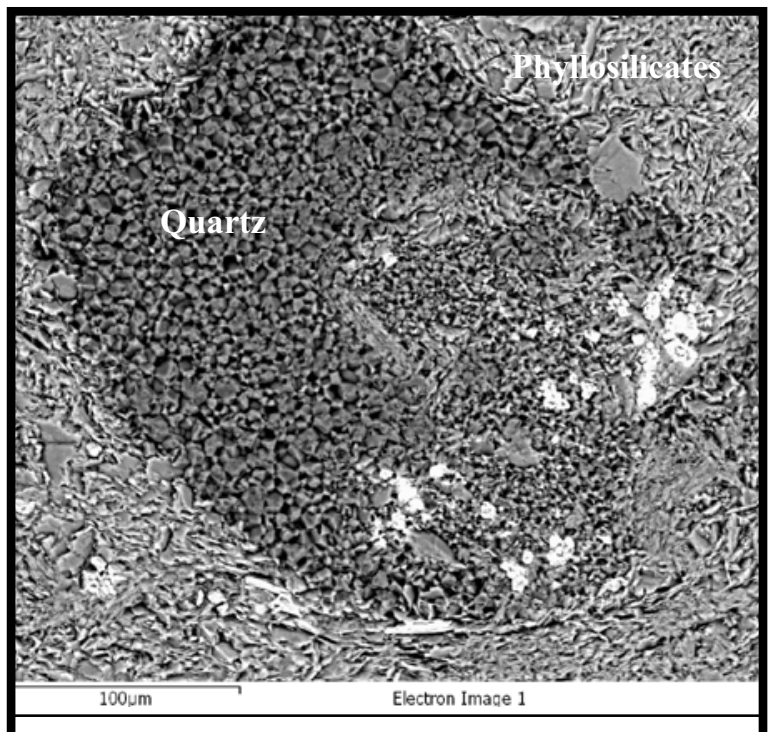

Figure 2

ESEM BSE image showing the abrupt boundary between the quartz and phyllosilicate phases. Brightest minerals are $\mathrm{TiO}_{2}$. Image acquired at $70.0 \mathrm{~Pa}$ pressure, $15 \mathrm{keV}$ accelerating voltage.

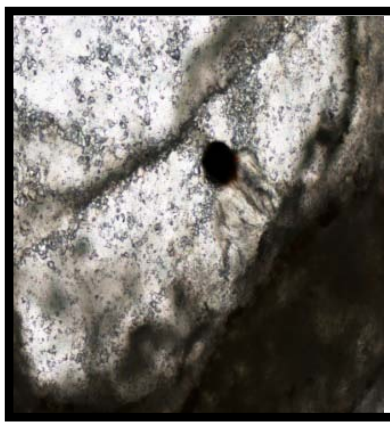

Figure 4

Microbial induced microtubular structure under PPL. Pyrite grain is moved by gas from decay of organics.
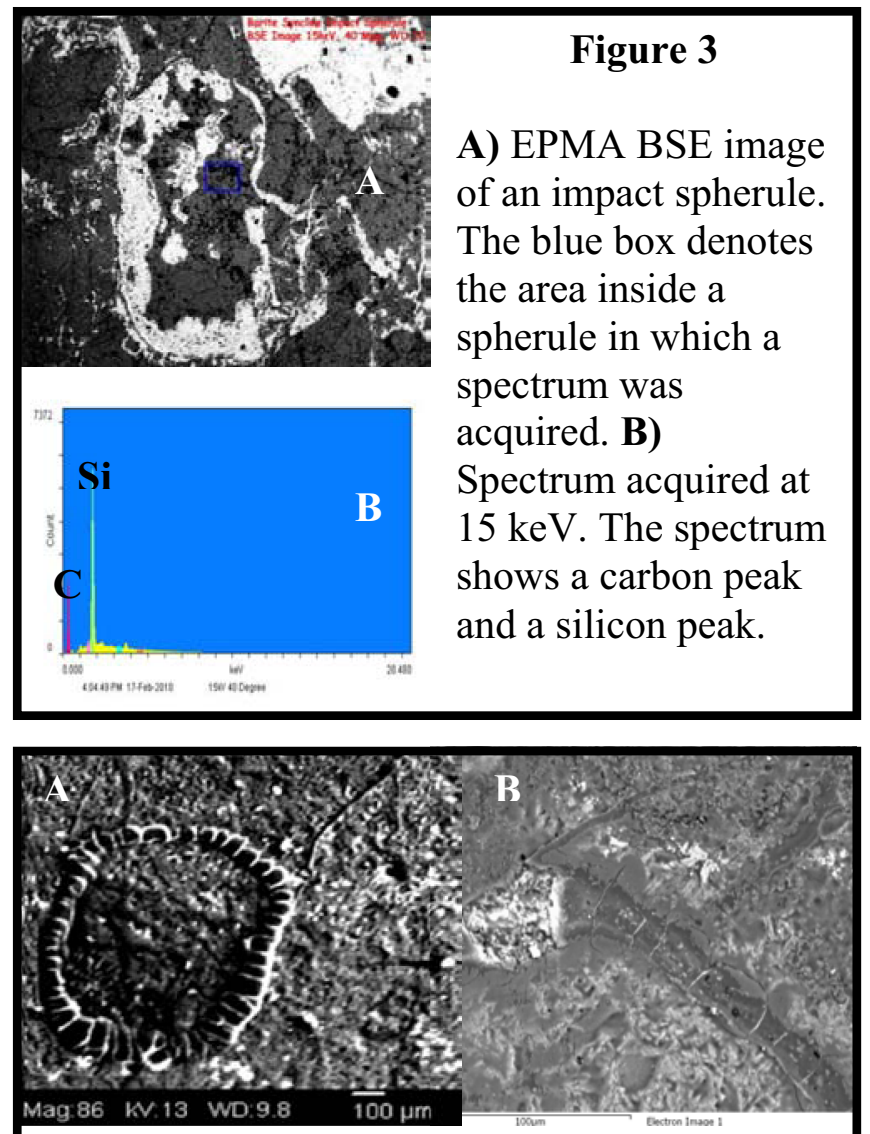

Figure 5

A) EPMA BSE image of structure with cyanobacteria-type morphology. Image acquired at $13 \mathrm{keV}$ accelerating voltage. B) ESEM of same structure at higher magnification. Image acquired at $70.0 \mathrm{~Pa}$ pressure, $15 \mathrm{keV}$ accelerating voltage with solid-state BSE detector. 